\title{
NURSING CARE AMONG POSTPARTUM PATIENTS WITH MILIARY TUBERCULOSIS BY THE EMPLOYING CULTURAL SENSITIVITY AND PORTABLE HEPA FILTER IN INTENSIVE CARE UNIT: A CASE STUDY
}

\section{Dede Wirdah Budiastuti ${ }^{1}$ Agung Waluyo ${ }^{2}$ Juliana GEP Massie ${ }^{1}$ Maria Pele $^{1}$ Nisa Utami ${ }^{1}$ Novi Pampalia ${ }^{1}$ Qurratu Iffoura ${ }^{1}$}

\section{Postgraduate Student, Faculty of Nursing, Universitas Indonesia}

2. Faculty of Nursing, Universitas Indonesia

*. Correspondence : dede.wirdah71@ui.ac.id

\begin{abstract}
Nursing care services for post-partum patients with medical diagnoses of Miliary Tuberculosis (TB) in the Adult Intensive Care Unit (ICU) require a comprehensive approach. Critical nursing care with ICU settings and the use of portable HEPA filter are employed as alternatives if the ICU does not have an isolation room. Therefore, ICU nurses must concern the patient's needs, both the socio-cultural and cultural bio psycho. Rehabilitating patients in isolation rooms or using a portable HEPA filter that makes the patient's situation isolated results in patients' uncomfortable and restless feeling. In this case, the treated patient hold Middle East culture, and thus, she concerns about covering her head as part of her religious and cultural teachings. However, wearing headgear or hijab is rarely considered in the ICU because ICU nurses prioritize the critical condition of patients as the most vital regard to consider. This case study describes how to provide care to patients in ICU with the use of portable HEPA filter as an alternative TB isolation room and a culturally sensitive approach to meet the socio-cultural needs of the patient. Therefore, she feels comfortable and safe in the ICU room.
\end{abstract}

Keywords: Miliary TB, portable HEPA filter, cultural approach

International Journal of Nursing and Health Services (IJNHS), September 2019, Volume 2, Issue 3; Page 58-79

Received: 10 March 2019; Revised: 14 April 2019; Accepted: 07 May 2019

DOI: http//doi.org/10.35654/ijnhs.v2i3.119

\section{Introduction}

Tuberculosis still becomes a global problem. For the last two decades, there is a significant change in the epidemiology of TB cases with the increase of migration, the involvement of HIV infection, and disease incidence at a younger age. In global, the prevalence and the number of death caused by TB decrease (1). However, the impact of this disease significantly reaches more than ten million cases, and one million ends, as recorded in 2015 (1). Though the data denote a high level of success up to 83\% for TB treatment, healthcare for TB patients with multiple organ dysfunctions in the Intensive Care Unit (ICU) can worsen prognosis. Delayed diagnosis and initiation treatment are frequently caused by less recognition in several countries with low incidence. This becomes one of the main contributors of death caused by this disease (2). 
Of 20 countries, Indonesia is the second greatest country with TB sufferers, just after India, with 10.3\% global TB (1). Whereas, 2015 Global Report of WHO releases that Indonesia was the fourth greatest country with TB sufferers just after India, China, and South Africa in 2010. (3) Posits that the prevalence of Indonesians diagnosed with TB by health professionals in 2013 is $0.4 \%$. Five provinces with the biggest TB sufferers are West Java (0.7\%), Jakarta (0.6\%), Papua (0.6), Gorontalo (0.5\%), Banten (0.4), and West Papua (0.4\%).

Several TB cases in England healthcare services indicate a significant difference of incidence on the population of pregnant and non-pregnant women. Previous research posits that women with TB tend to come from minority ethnics, have non-specific symptoms, frequently receive late diagnoses, and suffer from extrapulmonary tuberculosis (4). Miliary tuberculosis is $2 \%$ of overall TB cases and $20 \%$ of extrapulmonary tuberculosis cases. In HIV cases, $50 \%$ of extrapulmonary TB found on TB and miliary TB cases (5).

Tuberculosis incidence of pregnancy significantly increases. It has similar-clinical symptoms to those on non-pregnant women. Late diagnose is probably caused by initial symptoms which do not occur correctly. Offering appropriate and adequate regimen will improve the life quality of the mother, decrease the side effects of TB drugs on a fetus's growth, and prevent infections on newborn baby (6). The researchers manage a case of a postpartum patient in adult ICU with the assistance of mechanical ventilation. The patient receives specific nursing care because she has a unique culture of Middle East countries. This situation triggers the researchers to analyze the nursing care for miliary TB in pregnancy in ICU by employing cultural sensitivity theory.

\section{Objective}

To examine nursing care among postpartum patients with miliary tuberculosis by employing cultural sensitivity and portable HEPA filter in an intensive care unit

\section{Theoretical Framework}

A. Miliary TB

Miliary TB is a form of tuberculosis characterized by the wide dissemination of hematogenous from Mycobacterium tuberculosis into the human body (7). Another definition proposes that Miliary TB is wide dissemination of TB germs into several parts of the human body hematogenous through blood flow and lymph (8-9). Radiologically, military TB is a group of lung opacity cells with similar size and disseminates with the diameter less or similar to 2 millimeters (5). Miliary TB is caused by primary diseases or recurrence of latent TB (8).

TB infection starts when a sufferer inhales Mycobacterium tuberculosis bacillus. These bacteria will disseminate through aspiration towards alveolus, then they reproduce and accumulate.

Miliary TB occurs because of the massive spread of mycobacterium tuberculosis through lymph and embolization of several organs, such as the liver, lymph, spinal cord, spinal cord, lungs, and meninges.

This happens because of the number of phagocytic cells in the sinusoidal walls of the organs.

After early infection, if the response of the immune system is inadequate, the 
disease will be severe. The severe illness is possibly caused by reinfection or reactivating previous-inactive bacteria. It occurs since the effector $\mathrm{T}$ cells are insufficient to oppress mycobacterium tuberculosis. Consequently, they grow as miliary TB (10).

Miliary TB is derived from the word Miliet, which means millet or small grains, and they are palpably visible on granulomatous nodules of miliary TB in the form of small grains. Radiology images or CT Thorax will palpably indicate patterns of miliary TB on patients with TB. Miliary patterns occur for 50\%. Asymmetric patterns of nodules, airspace consolidation, coalescence nodules, mottled appearance snowstorm, and ground glass occur for around 10-30\%. Meanwhile, parenchymal lesions and cavitation, segmental consolidation, interlobular septal thickening, pleural effusion, empyema, pneumothorax, pneumomediastinum, intrathoracic lymphadenopathy, and pericardial effusion occur for $<5 \%$. Performing thoracic and abdominal paracentesis allows examination of pleural fluid and peritoneum. The investigation is possibly assisted by employing USG guide (5).

Laboratory results reveal pancytopenia, hypoplastic anemia, and hypercalcemia as the results of immunological mechanism, which cause pressing on spinal cords. Furthermore, hyponatremia is found as an indication of TB meningitis, a predictor of death on miliary TB, and a malfunction of Antidiuretic Hormones.

Miliary TB increases with HIV cases, human organ transplants, use of immunosuppressive drugs, and an increase in chronic hemodialysis programs. On patients with miliary TB, various predisposition factors such as infection when small, malnutrition, HIV/AIDS, alcohol, CKD, dialysis, post gastrectomy, human organ transplantation, the use of immunosuppressive drugs, connective tissue disorders, pregnancy, postpartum, ferocity, silicosis, DM, and smoking are found (5).

In the National TB control program, diagnosing lung TB in adults must formerly be conducted by bacteriological examination and rapid test. The examination consists of direct microscopic examination, culture, and rapid diagnostic test. Morning sputum of suspected TB patient is tested. If at least, one of morning sputum tests is positive AFB, the patient is diagnosed as suffering from TB. If the bacteriological analysis indicates a negative result, TB diagnosis can be conducted clinically by employing the results of clinical and supporting tests (at least chest radiographs) which are appropriate and determined by specialist TB doctors. Diagnosing TB by only serological examination, tuberculin test, and chest radiographs is not justifiable. Chest radiographs do not always provide a specific image of Pulmonary TB. Therefore, it probably causes overdiagnosis or underdiagnosis.

\section{Diagnosis of Extrapulmonary TB}

Symptoms and complaints depend on an infected organ, for examples, stiff neck for TB meningitis, chest pain for TB pleural (pleuritic), enlarged superficial lymph glands for TB lymphadenitis, and spinal deformity (gibbus) for TB spondylitis and others. Definitive diagnosis in patients with extrapulmonary TB is executed by clinical, bacteriological, and histopathological test from the test samples taken from infected organs. Bacteriological test can be executed if appropriate complaints and symptoms are found to find any possibility of pulmonary TB. 


\section{Management of Miliary TB}

a. Medication Management

The treatment of TB in Indonesia has the guidance of antituberculosis drugs campaigned by National TB Control Program in Indonesia. The treatment consists of:

1) Category 1:2 (HREZ)/4(HR)3

2) Category 2: 2(HREZ)S/(HRZE)/5(HR)3E3.

3) Child category: 2(HRZ)/4(HR) or $2 \mathrm{HRZA}(\mathrm{S}) / 4-10 \mathrm{HR}$

4) Drugs used in the management of TB patients in Indonesia consist of second-line antituberculosis drugs, such as Kanamycin, Capreomycin, Levofloxacin, Ethionamide, Sikloserin, Moksifloksasin, and PAS, and first-line antituberculosis drugs, such as Pyrazinamide and Ethambutol.

The guidance of antituberculosis drugs of category 1 and two are provided in the form of fixed-dose combination drugs. It is two or more drugs contained in a single dosage form, such as a capsule or tablet. The dosage is adjusted with patients' weight.

Certain conditions, such as pregnancy and breastfeeding, are similar to that of common TB condition. All types of antituberculosis drugs are safe for breastfeeding mothers. Breastfeeding mothers suffering from TB must receive adequate guidance of antituberculosis drugs. Appropriate antituberculosis drug distribution is the best way to prevent contagion of TB germs to the baby. Mother and her baby are not necessarily separated, and she can continuously breastfeed.

\section{b. The Management of Non-Medication}

The management of TB patients is not only in medication but also in patients' healthcare environment, such as occupying patients in an isolation room with negative pressure and using personal protective equipment for healthcare professionals treating the patients. A good isolation room with negative pressure and HEPA filter system is recommended for the management of TB nursing rooms.

\section{The Work of HEPA Filter}

The HEPA filter is one of the vital components in the HVAC system. HVAC stands for Heating, Ventilation, and Air Conditioning. It is frequently called as a system of air management or a system which conditions environment by controlling temperature, relative humidity, air movement direction, and air quality, as well as controlling particles and contaminant removal in the air. HEPA stands for HighEfficiency Particulate Air which is initially called as a high-efficiency particulate absorber, and it is occasionally called as high-efficiency particulate arresting or highefficiency particulate arrestance.

HEPA Filter is approved by Centres for Disease Control and Prevention to have an important role in resisting infectious airborne pathogen and harmful air particles. Mikropor HEPA filter is designed to remove particulates and pathogen efficiently.

\section{Portable HEPA Filter}


Portable HEPA is a highly efficient and applicable particulate system which is simply and economically designed to create an isolation room with negative pressure which will fill the guidance of OSHA and CDC TB. HEPA is possibly used as a positive system of air circulation in clinical rooms, waiting rooms, ICU rooms, and other restricted areas; or as a system creating an isolation room with negative pressure to enable suspected TB patients, SARS, or other contagious diseases to occupy the rooms.

As a circulation unit, fan motor of portable HEPA can produce up to $1500 \mathrm{CMH}$ and supply air to the rooms to minimize the dissemination of diseases in the air to patients and health professionals. As a negative pressure unit, air passing HEPA filter is cleaned from particles for $99.97 \%$ or as much as 0.3 Micrometre, and it can be directly removed through windows by only connecting flexible ducting to 6 inches 152 millimetres located on the upper part of portable HEPA. Portable HEPA has several advantages. 1) It is initially designed to be used in an emergency and temporary situation, for instance: facility of surgical operation in war, natural disaster, or pilot project. 2) It does not require a long time to install or transfer the unit from one place to another. Furthermore, its use is limited in not-wide rooms. 4) It can remove bacteria and dust. 5) It can remove chemical contaminants. 6) It can remove the virus and bacteria. 7) Its design is minimalist and very portable. 8) It has an indicator for filter and unit with energy-saving airspeed controllers. 9) It requires easy maintenance. On the other hand, portable HEPA has several disadvantages. 1) It is not recommended for a hospital with central air management of surgical installation. 2) It is commonly indented and not ready stock in a market. 3) Spare parts of HEPA filter elements have customized size and depends on its producers. 4) It has limited capacity for air volume and air pressure. 5) It requires additional air duct by perforating the wall of operating theatre to release air or receive fresh air. 6) The lifetime of its filter elements is shorter than permanent HEPA systems. 7) It only functions as an air sterilizer or purifier, and it does not synergize directly to the cooling system, such as central AC.

\section{B. Culturally Sensitive Approach}

Culturally sensitive nursing care is nursing care employing cultural competence in assisting patients to fulfill their needs based on their cultural needs (11). The research of (11) Novieastari et al. (2018) conducted in 2012 reveals that patients received nursing care from nurses with cultural sensitivity skill feel more satisfied with the services than those received nursing care from nurses without cultural sensitivity competence or ability. It indicates that patients in Indonesian have cultural, traditional, and religious diversity.

Therefore, providing nursing care by considering the religious and cultural needs of patients is necessary. Nursing care in ICU requiring responsive and fast services occasionally ignore culture. A threatening situation to patients' emergency condition poses a priority for nurses in providing nursing care. Therefore, when patients are treated in ICU, it is substantial that the nurses comprehensively understand the patients' need, including spiritual and cultural need besides providing critical nursing care.

\section{Methods}


The Design used in this study is a case study. The patient in this case study is a young woman with Miliary TB, postpartum, and isolated with the use of Hepa Filter Portable. Nursing care provided to patients with miliary TB includes comprehensive assessments, such as biological, psychological, spiritual, and cultural care, because clinical manifestation on TB patients can influence their lifestyle particularly in miliary TB which influences another organ except for the lungs. When assessing, clinical manifestation on TB patients include pyrexia with the increase in body temperature at night, weight loss, anorexia, tachycardia, and night sweats for more than six weeks.

Based on supporting medical information, diagnosing miliary TB is perplexing because clinical manifestation is not specific and atypical. Chest radiology does not indicate data in the early infection. Therefore, systemic approach is necessary. Cardiac tamponade and ARDS of patients with dyspnea is compulsorily evaluated. Furthermore, Lumbal puncture test is required for TB meningitis. The results of tuberculin and IGRA test can indicate the emergence of TB infection, but it is not always active. Tuberculin energy usually occurs in $20-70 \%$ of adult patients with miliary TB. Several nursing care problems that possibly emerge in patients with miliary TB are: 1) ineffective airway clearance associated with accumulation of secretions in the airway, 2) ineffective breathing patterns related to expansion and pulmonary recoil disorders, 3) disruption of gas exchange with alveolar-capillary membrane changes, 4) spontaneous ventilation disorders associated with metabolism disorder, 5) nutritional deficits related to anorexia, 6) hyperthermia associated with an inflammatory reaction to bacterial infections, 7) fatigue associated with metabolism disorders, and 8) anxiety-related to lack of knowledge of disease and medication mechanisms. Several nursing intervention plans based on those problems are Airway Management, Cough Enhancement, Vital Sign Monitoring, Oxygen Therapy, Positioning, Tube care: Chest, Acid-base Management, Oxygen Therapy, Vital Sign Monitoring, Ventilation Assistance, and Mechanical Ventilation Management: Invasive or Non Invasive, Airway Suctioning, Nutrition Management, Fever Treatment, Infection Control, Infection Protection, Fluid Management, Medication Management, Energy Management, Exercise Promotion, Activity Therapy, Anxiety Reduction and Relaxation Therapy.

\section{Results}

Case. The patient is a 23-year older woman who works as a teacher. She is an Arab descent and Muslim who lives in Jakarta. She was hospitalized in ICU because of being referred by another hospital. She was early diagnosed as having type 1 respiratory failure with delivery G1P0A0 and estimated parturition 09/16/2018. She regularly checked her pregnancy in a midwife and underwent USG for three times. She had complained chest tightness since a day before she was hospitalized. She received therapy to decrease chest tightness. She suffered from a cough for one-month pregnancy. Before being hospitalized, she did not suffer from heartburn, the water did not come out, a fetal motion was normal, defecation and urination patterns were normal, and fetal condition was critical. She had been hospitalized in ICU since September 14, 2018, and was diagnosed with a post-cesarean section with critical fetal, pneumonia, and miliary TB. The result of thorax images indicated a specific description of miliary TB. Several laboratory tests, such as AFB test 1,2, and 3 showed a negative effect, and germ sputum culture found was streptococcus viridian. Antituberculosis 
drugs and antibiotics were given under the type of medicines which was sensitive to the result of a sputum culture test.

Since the ICU did not have a standardized isolation room to treat patients with miliary TB, the patient was treated in a cohort unit with a portable HEPA filter. Nurses who treated her use N-95 mask and conducted a universal precaution. She was intubated by the use of mechanical ventilation and closed weaning. Heat Moisturiser Exchanger (HME) with anti-bacterial was set by the hospital standards. In the seventh nursing day, she could perform a spontaneous breathing trial, and she was extubated. Her weak condition after delivery and not seeing her baby became risky factors causing her to suffer from post-partum blues depression. She consulted psychiatry and received therapy. She received therapeutic communication by involving her husband and parents to decrease her anxious response. Since she usually wears her hijab, she also wore it during the treatment. Her husband and parents were encouraged to create a video and show the pictures of the baby to her. Therefore, she could see the development of her baby. Breastfeeding could not be conducted because her condition was not stable, and mastitis condition was not found.

She was restless because of being isolated from other patients. It occurred since her room was set with a portable HEPA filter. Education and communication were conducted by giving an explanation to the patient about the benefits of the portable HEPA filter. However, she still received the best treatment though she was isolated.

\section{Discussion}

Patient's nursing care in ICU is a sophisticated and multi-factor service, and it involves an elaborate intervention plan. Accuracy and focus on the services are necessary. When providing nursing care, holistic nurses necessarily ascertain sensitive things. Ensuring nursing care by regarding patients' cultural need is needed for each clinical arrangement. However, the characteristics of patients' intensive care and severe illness demand the increase of needs, and they depend on nurses' attitude as well as values and systems believed. It is mainly performed when providing holistic nursing care for people from various ethnics and cultures (12).

The case in this research is an Arabic woman with postpartum, miliary TB, and respiratory failure. The setting of ICU is arranged by the principles of infection prevention and control by employing a portable HEPA filter. The patient is isolated by setting barrier with other patients. One of the patient safety targets is to prevent the occurrence of contagious illness to other patients or health professionals. Therefore, in this case, the patient probably feels isolated and anxious about receiving different treatment from other patients. It is significant that other nurses explain and educate the patients about the importance of using an isolated room and HEPA filter.

The use of a HEPA filter in a room is believed to decrease the risk of infectious disease transmission through particle removal or droplet with big size and containing pathogen from infectious infection. The use of portable HEPA filter in hospital wards aims to increase the level of effective ventilation (only for particle) and effective airflow rate in general ward to adjust to standards of an isolation room for in an infectious patient with the rapid occurrence and spread. It is probably the best solution for patients in a hospital with an inadequate number of isolation rooms.

A trial conducted in research to investigate the effectiveness of portable HEPA filter indicates that a portable HEPA filter effectively decreases the concentration of 
particles (13). An explanation is provided to the patient as well as her family as a prominent supporter for her recovery. Furthermore, the nurses concern the patients' needs of bonding attachment with her baby because from the delivery process to occupying ICU room, she has not seen her baby. It occurs since her hemodynamics condition is extremely labile, and thus, the focus of treatment is on monitoring the hemodynamics. During her treatment in ICU, she does not breastfeed as well as indicate mastitis.

Nurses motivate the patient's family to take pictures, make videos of the baby, and show them to her during the visit. This will encourage her to recover. Family is a primary institution in Muslim society. The decision for any crucial problems, such as health and treatment are made collectively, and all family members commonly attend delivery process, visit sick people, or attend the funeral ceremony (14). Based on the consideration of comprehensive nursing care, it is essential that the nurses consider culturally sensitive nursing care in an ICU setting. This nursing care not only focuses on hemodynamics but also concerns cultural sensitivity, for example, regarding spiritual needs. In this case, the patient is a Muslim woman. She covers her head with hijab every day. However, in her first treatment in ICU, she is not allowed to wear hijab. Therefore, sensitive nursing care toward the patient's spiritual aspects is necessary. Wearing hijab can give comfort to the patient because she requires fulfilling her religious and cultural needs.

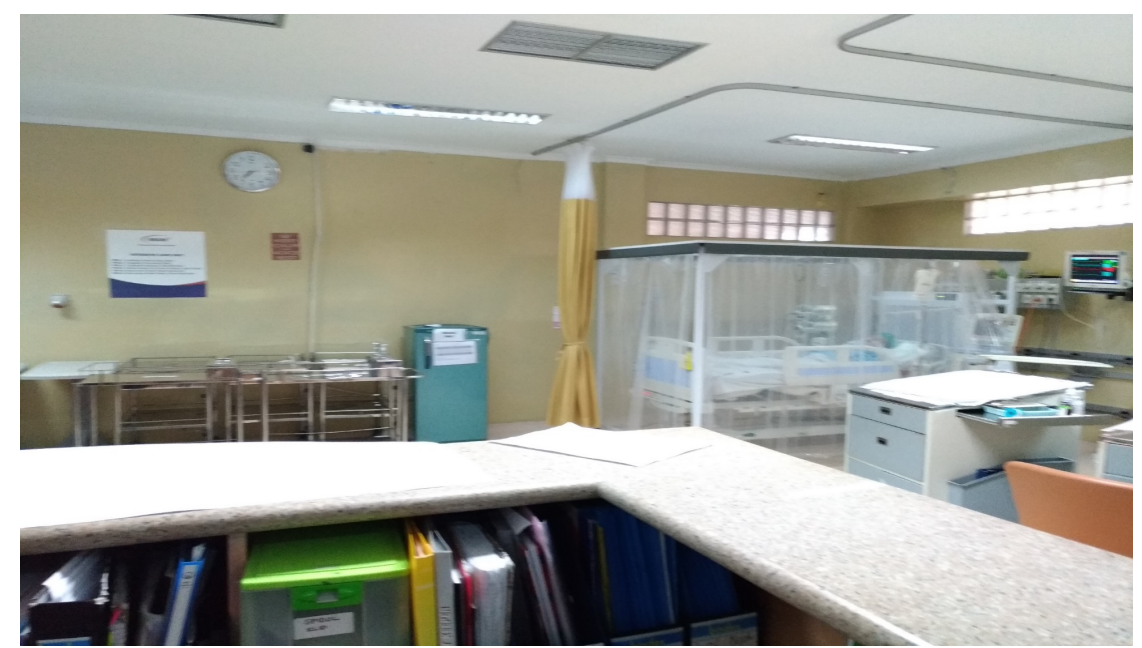

Picture 1: Portable HEPA Filter in ICU Room

\section{Wearing Hijab for Patients in ICU}

For a Muslim woman, covering the head with hijab is a religious obligation. Hijab is not merely a demand in Islamic dressing, but it becomes an identity of a Muslim woman. Wearing hijab is probably performed by nurses for the patient by putting hair cap or veil on her head though she is unconscious. ICU nurses necessarily question the patient's daily dressing style to her family. When the ICU team provide information and education to the patient's family for the first time she occupies ICU room, the nurses can question her daily dressing style. Nurses can put hair cup when the patient is unconscious because it will not disturb any nursing activity for her. Furthermore, if she 
has been conscious, her condition is stable, and her breathing patterns are spontaneous, nurses can directly put the hijab on her head.

\section{Conclusion and Recommendation}

Miliary TB is an illness caused by the wide dissemination of TB germs into several parts of the human body through lymph and blood circulation. Miliary TB possibly causes complications, such as respiratory failure, and thus, a patient requires specific nursing care and monitoring in ICU. Besides improving the hemodynamic condition, the use of portable HEPA filter is vital to prevent the transmission of TB germs to other patients. However, the treatment compulsorily concerns the comfort of patients and their family, and thus, nurses necessarily provide accurate explanation and education related to this condition. Moreover, nurses fundamentally consider patients' needs based on their culture and religion. In this research, a patient's wearing hijab in ICU requires consideration. Nurses can assist the patient in fulfilling her spiritual, cultural, and individual requisites though she is treated in an ICU room and isolated. By concerning culturally sensitive aspects, nursing care services in ICU possibly provide more comfort to patients and their family.

\section{References}

1. World Health Organization. WHO treatment guidelines for drug-resistant tuberculosis. 2016.

2. Singh K, Hyatali, S., Giddings, S., Singh, K., \& Bhagwandass N. Miliary tuberculosis presenting with ards and shock: a case report and challenges in current management and diagnosis. 2017.

3. Kementrian Kesehatan RI. Hasil Utama Laporan Riskesdas 2018. Jakarta Badan Penelit dan Pengemb Kesehat Dep Kesehat Republik Indonesia. 2018;

4. Kwan, B. C. H., Yu, Y., \& Goldberg H. A case of tuberculosis in a pregnant woman and review of current literature. Obstet Med. 2010;3(4):161-3.

5. Sharma SK, Mohan A SA. A new look at an old foe. J Clin Tuberc Other Mycobact Dis. 2016;3:13-27.

6. Meiyanti M. Penatalaksanaan tuberkulosis pada kehamilan. Universa Med. 2016;26(3):143-51.

7. Werdhani RA. Patofisiologi, diagnosis, dan klafisikasi tuberkulosis. Jakarta: Departemen Ilmu Kedokteran Komunitas, Okupasi, dan Keluarga FKUI; 2002.

8. Lewis, S., Dirksen, S., Heitkemper, M., Bucher, L., \& Camera I. Medical surgery nursing assessment and management of clinical problems. 2011.

9. Matsuura, H \& Nakatsu M. Clinical picture: Miliary tuberculosis. QJM An Int J Med. 2017;683.

10. Ray S, Talukdar, A., Kundu, S., Khanra, D., \& Sonthalia N. Diagnosis and management of miliary tuberculosis: Current state and future perspectives. Ther Clin Risk Manag. 2013;9(1):9-26.

11. Novieastari E, Gunawijaya, J., \& Indracahyani A. Pelatihan Asuhan Keperawatan Peka Budaya Efektif Meningkatkan Kompetensi Kultural Perawat. J Keperawatan Indones. 2018;21(1):27-33.

12. Bloomer MJ, Al-Mutair A. Ensuring cultural sensitivity for Muslim patients in the Australian ICU: Considerations for care. Aust Crit Care [Internet]. 2013;26(4):193- 
6. Available from: http://dx.doi.org/10.1016/j.aucc.2013.04.003

13. Qian H. L, Y. et al. Particle removal efficiency of the portable HEPA air cleaner in a simulated Hospital ward. Berlin Heidelberg: Tsinghua University Press; 2010.

14. Obeidat $\mathrm{H}$, \& Callister, $\mathrm{LC}$. The lived experience of Jordanian mothers with a preterm infant in the neonatal intensive care unit. J Neonatal Perinatal Med. 2011;4(2):13745. 